\title{
Electron Paramagnetic Resonance Characterization of a Humic Acid-Type Polymer Model
}

\author{
Marcilene F. Barriquello, ${ }^{*, a}$ Sergio da Costa Saab, ${ }^{b}$ Nelson Consolin Filho ${ }^{c}$ and \\ Ladislau Martin-Neto ${ }^{d}$
}

anstituto Federal de Educação, Ciência e Tecnologia do Acre, 69900-000 Rio Branco-AC, Brazil

${ }^{b}$ Departamento de Física, Universidade Estadual de Ponta Grossa, 84030-900 Ponta Grossa-PR, Brazil

${ }^{c}$ Centro de Ciência Biológicas e da Natureza, Universidade Federal do Acre, 69900-000 Rio Branco-AC, Brazil

${ }^{d}$ Embrapa Instrumentação Agropecuária, CP 741, 13560-970 São Carlos-SP, Brazil

\begin{abstract}
Modelos de ácidos húmicos do tipo poliméricos tem mostrado semelhanças químicas com os ácidos húmicos naturais $(\mathrm{AH})$. Devido à complexidade das substâncias húmicas $(\mathrm{SH})$, esses modelos de ácidos húmicos do tipo poliméricos, no qual os sítios ligantes podem ser melhores definidos, podem ser usados no estudo de metais e outras aplicações. Neste estudo, obteve-se um polímero com características análogas às dos $\mathrm{AH}$ coletados em área de cultivo com sistema plantio direto por 9 anos, por meio de reações de síntese, através da polimerização oxidativa em meio alcalino utilizando como precursor a para-benzoquinona. Foi realizado um estudo do ácido húmico (AH) e do ácido húmico sintético (AHS) utilizando espectroscopia de ressonância paramagnética eletrônica (RPE). O sinal dos radicais livres do tipo semiquinona foi detectado para o AHS. Nos espectros observam-se sinais semelhantes entre o AH de solo e o AH sintético complexado com íons $\mathrm{Fe}^{3+}, \mathrm{Cu}^{2+}$ e $\mathrm{Mn}^{2+}$.
\end{abstract}

Humic acid-type polymer models have been shown to be similar to natural humic acids (HA) in terms of chemical properties. Due to the complexity of humic substances (HS), this humic acid-type polymer models, in which the ligand sites are better defined, can be used in the study of metals and for other applications. In this study, a polymer with characteristics analogous to those of humic acids isolated from soil surface cultivated using a no-tillage system for nine years, was obtained by means of synthesis reactions, through oxidative polymerization in an alkaline medium using para-benzoquinone as precursor. An EPR spectroscopy study was made of natural humic acids (HA) and synthetic humic acids (SHA). A semiquinone-type free radical signal was detected in the SHA. The spectra showed similar signals for HA from soil and synthetic HA complexed with $\mathrm{Fe}^{3+}, \mathrm{Cu}^{2+}$ and $\mathrm{Mn}^{2+}$ ions.

Keywords: synthetic humic acid, metal cations, EPR

\section{Introduction}

Humic substances (HS) are well known for being the major component of soil organic matter (SOM) and for their ability to interact with various elements of the environment. HS play a significant role in soil and aquatic chemistry.

*e-mail: mferrarib@hotmail.com, marcilene.barriquello@ifac.edu.br
HS constitute almost all the organic matter of soil, and due to their high reactivity, they are the fraction involved in most of the chemical reactions that occur in soil. The chemistry and structure of HS are highly complex, which is why their molecular formula is not well defined. ${ }^{1}$ Depending on the source of organic material involved in the humification process, HS have a variety of molecular structures that differ according to their source. Analytical limitations and complex and dynamic nature of SOM 
make difficult its characterization. To obtain further information about the chemical structure of the HS, synthetic compounds with polymeric chains have been used whose characteristics are analogous to those of HS, such as phenolic polymers..$^{2-6}$ Zunino et al. ${ }^{7}$ used models of polymeric-type humic and fulvic acids to study the competitive behavior of $\mathrm{Zn}^{2+}$ and $\mathrm{Mg}^{2+}$. Significant progress in the study of metals can be achieved using polymers as models similar to HS, in which the ligand sites are better defined, since functional groups and electron donor atoms can be defined using specific precursors.

The literature contains several examples of the application of electron paramagnetic resonance (EPR) in the study of HS. ${ }^{8-10}$ EPR spectroscopy is one of the only techniques that can supply structural information, without artifacts or restrictive experimental conditions, about the complexation of metallic ions $\left(\mathrm{Fe}^{3+}, \mathrm{Cu}^{2+}, \mathrm{Mn}^{2+}, \mathrm{VO}^{3+}, \mathrm{Cr}^{3+}\right.$ and others) with HS from soils, water and sediments. ${ }^{11}$ EPR can also detect free radicals in HS, determining their concentration and sometimes their origin. HS contain stabilized free radicals in their structure, and it has been proposed that they may be associated with polymerization/ depolymerization reactions, and with the degree of aromaticity and humification of organic matter, possibly interacting with pesticides and toxic organic pollutants. ${ }^{11}$

MacCarthy ${ }^{12}$ postulated that humic substances are unique in nature and have qualities unlike any other natural substances. The first principle postulates that humic substances represent a supermixture of an extremely wide array of chemical structures. Thus, the probability of finding two identical structures is exceedingly remote. ${ }^{13}$ Humic substances, of which humic acid (HA, insoluble at acidic $\mathrm{pH}$ ) and fulvic acid (FA, water-soluble at acidic to alkaline $\mathrm{pH}$ ) are the major fractions, present various chemically reactive functional groups, including carboxyls, and phenolic and alcoholic hydroxyls with $\mathrm{pH}$-dependent properties. ${ }^{14}$ This diversity of their chemical composition allows HS to be used in different situations. Venancio et al. ${ }^{15}$ demonstrated that the properties of HS can be used in the fabrication of sensor arrays for use in the classification of humic substances present in aqueous systems, as well as the possibility of using HS for the production of self-assembled films. A novel and simple method electrode with rapid preparation was developed with humic acid and polypyrrole. The modified electrode displayed good and reversible extraction properties. ${ }^{16}$ Some specific humic molecules play an important role in industrial and pharmacological applications, such as the production and use of therapeutic chemicals from humic acids and the manufacture of commercial humates for use in soils. ${ }^{17}$
Within this context, the objective of this research was to study polymeric models of humic acids, using EPR spectroscopy confronting the results with the HAs extracted from soil under no-tillage system for nine years.

\section{Experimental}

\section{Sample preparation}

Two different materials were evaluated, a natural humic acid (HA) extracted from a soil, and a compound synthesized (SHA) from para-benzoquinone. The soil sample used for the extraction of humic acid (HA) was collected from surface (0 to $25 \mathrm{~mm}$ ) an area under nine years of management, involving no-tillage system in the cultivation of oats with common vetch/corn with cowpea. The soil type corresponds to a Typic Paleudult by US taxonomy with 540 sand, 240 silt, and $220 \mathrm{~g} \mathrm{~kg}^{-1}$ clay. The clay fraction type is composed mainly of kaolinite ( $\left.720 \mathrm{~g} \mathrm{~kg}^{-1}\right)$ and iron oxides $\left(\mathrm{Fe}_{2} \mathrm{O}_{3}, 109 \mathrm{~g} \mathrm{~kg}^{-1}\right)$.

Humic acid (HA) was extracted from Paleudult soil, following the methodology proposed by the International Humic Substances Society (IHSS). ${ }^{18}$

The polymer (SHA) was prepared with $5.4 \mathrm{~g}$ of parabenzoquinone dissolved in $60 \mathrm{~mL}$ of water containing $2.8 \mathrm{~g}$ of $\mathrm{KOH}$. The solutions were placed in flasks and a stream of purified air was bubbled into them at a rate of $1 \mathrm{~L} \mathrm{~min}{ }^{-1}$. The air was purified by first passing it through solid $\mathrm{NaOH}$ pellets, after which it was bubbled in a solution of $0.8 \mathrm{~mol} \mathrm{~L}^{-1} \mathrm{NaOH}$. After $22 \mathrm{~h}$ of air bubbling, the resulting black viscous solutions were treated with $6 \mathrm{~mL}$ of concentrated hydrochloric acid under mechanical stirring until it precipitated into a brownish black mass. The polymeric products were collected by vacuum filtration, washed repeatedly with deionized water, and dried in air for one day and subsequently at $60{ }^{\circ} \mathrm{C}$ for one day.

\section{Preparation of synthetic humic acids (SHA) metal complexes}

Complexes of the polymeric SHA with the $\mathrm{Cu}^{2+}, \mathrm{Fe}^{3+}$ and $\mathrm{Mn}^{2+}$ ions were prepared by adding $0.1 \mathrm{~g}$ of each polymer to $40 \mathrm{~mL}$ of a $0.10 \mathrm{~mol} \mathrm{~L}^{-1}$ solution of each metal sulfate. The suspensions were shaken for $16 \mathrm{~h}$. The samples were centrifuged at 2,200 rpm for $20 \mathrm{~min}$ and the supernatant discarded. Deionized water $(10 \mathrm{~mL})$ was added, the solids shaken for $2 \mathrm{~min}$ and again centrifuged at 2,200 rpm for $20 \mathrm{~min}$, and the supernatant discarded. This washing procedure was repeated twice, after which the purified products were collected and freeze-dried. 


\section{Elemental analysis and determination of the ash contents}

The elemental composition of the resulting humic acids was characterized based on the quantification of nitrogen, carbon, hydrogen and sulfur, using a CHNS-O analyzer (CE-Instruments EAGER 200), and determination of the difference in percentage by mass of oxygen: $\% \mathrm{O}=100-[(\mathrm{C}+\mathrm{H}+\mathrm{N}+\mathrm{S}) \%]$.

The ash content was determined gravimetrically by weighing and calcining approximately $10 \mathrm{mg}$ of humic acid (HA and SHA) in a platinum crucible at a temperature of $600{ }^{\circ} \mathrm{C}$ until it reached a constant mass.

\section{EPR analyse}

The experiments were carried out with a Bruker EMX EPR spectrometer operating at X-band $(9 \mathrm{GHz})$, with a frequency modulation of $100 \mathrm{KHz}$, using a rectangular cavity. The samples were placed in a $3.5 \mathrm{~mm}$ diameter quartz tube, in duplicate, with a sample height of $50 \mathrm{~mm}$ and mass varying from 10 to $30 \mathrm{~g}$. The central field was $\mathrm{H}_{0}=340 \mathrm{mT}$, $v=9.72 \mathrm{GHz}$, and the microwave power was $0.2 \mathrm{~mW}$ with a modulation amplitude of $0.2 \mathrm{mT}$ at room temperature. The semiquinone-type free radicals were quantified by the secondary standard method, using a ruby crystal $\left(\mathrm{Al}_{2} \mathrm{O}_{3}\right)$ containing $0.5 \%$ of $\mathrm{Cr}^{3+}$ per weight. ${ }^{19}$ Its $g$ factor is 1.9797 and it therefore does not interfere with the signal of the semiquinone free radical, shoes $g$ values is around 2.003. ${ }^{20}$

To identify the metal ions complexed with HA and SHA, measurements were taken using the following parameters: for the $\mathrm{Fe}^{3+}$, the central field was $\mathrm{H}_{0}=286 \mathrm{mT}$, scan rate $\Delta \mathrm{H}=400 \mathrm{mT}$, frequency $\mathrm{v}=9.453 \mathrm{GHz}$, microwave power $=10 \mathrm{~mW}$, and modulation amplitude $=1.0 \mathrm{mT}$ at room temperature. The same parameters were used for $\mathrm{Cu}^{2+}$ and $\mathrm{Mn}^{2+}$, except that the scan rate was $200 \mathrm{mT}$ at room temperature and at the temperature of liquid nitrogen.

\section{Results and Discussion}

\section{Obtaining natural and synthetic humic acids}

In the extraction of humic acid from the soil, $710.5 \mathrm{mg}$ of humic acid per $0.08 \mathrm{~kg}$ of soil were obtained.

It is known that polyhydroxy phenols, as well as hydroquinones and quinones such as para-benzoquinone, are highly sensitive to the action of aqueous alkali solution, yielding polymeric products known as synthetic humic acids (SHA). ${ }^{21}$ The reason for synthesizing these polymers was that the information obtained from these synthetic precursors can be used to shed light on the complex structure of natural humic acids.

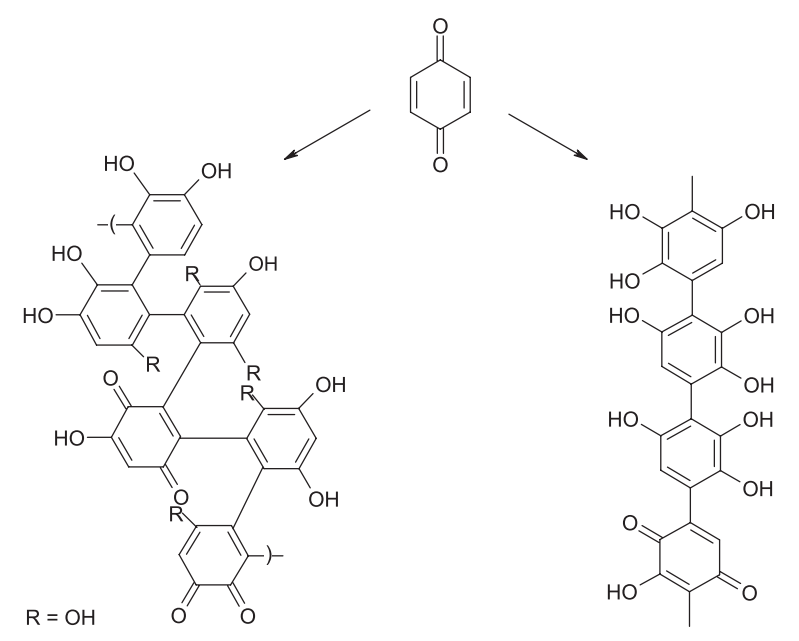

Figure 1. SHA obtained by oxidative polymerization in alkali.

The SHA polymer formed from the para-benzoquinone reaction provides a compound composed mostly of polyhydroxy phenols, in which the main adsorbing groups are $-\mathrm{OH}$ and $-\mathrm{COOH}$. This structure can be described by a sequence of phenyl rings having three hydroxyl groups per ring intercalated by monohydroxylated quinone units (Figure 1). ${ }^{21}$ The presence of the carboxylic group is derived from the degradation of the aromatic ring during polymerization. This structure is similar to lignin, one of the major constituents of the organic matter of soil. ${ }^{21}$

The SHA synthesis presented an excellent performance, yielding $76.36 \%$ in weight of polymerized parabenzoquinone.

\section{Elemental analysis and determination of ash content}

Table 1 lists the results of the elemental analysis and the ash content, indicating that the SHA contained a large amount of oxygen exceeding $40 \%$ (values calculated by difference), which is similar to the amount of oxygen found in natural humic acid, which also contains more than $40 \%$ of oxygen. According to Schnitzer and Kahn, ${ }^{22}$ the elemental composition of humic acids contains average amounts of 53.8-58.7\% of carbon, 3.2-6.2\% of hydrogen, $32.8-38.3 \%$ of oxygen, $0.8-4.3 \%$ of nitrogen and $0.1-1.5 \%$ of sulfur. These values are similar to the ones obtained from the HA extraction. The synthesized polymer differed only in the values described by Schnitzer and Kahn for sulfur and nitrogen content of SHA, which was expected due to the precursor compounds.

\section{EPR study}

Figure 2 shows the EPR spectra of the SHA and HA samples. These signals are typical of organic free 
Table 1. Elemental compositions of humic acid isolated from soil (HA) and synthetic humic acids (SHA) (given as percentages of ash-free substance basis)

\begin{tabular}{|c|c|c|c|c|c|c|}
\hline \multirow[t]{2}{*}{ Samples } & $\mathrm{N}$ & $\mathrm{C}$ & $\mathrm{H}$ & $\mathrm{S}$ & $\mathrm{O}^{*}$ & \multirow{2}{*}{$\begin{array}{c}\text { Ash content } \\
\%(\mathrm{~m} / \mathrm{m})\end{array}$} \\
\hline & \multicolumn{5}{|c|}{$\%$} & \\
\hline HA & $3.90 \pm 0.01$ & $44.50 \pm 0.01$ & $4.91 \pm 0.01$ & $0.71 \pm 0.02$ & $45.99 \pm 0.02$ & 7.0 \\
\hline SHA & $0.30 \pm 0.01$ & $55.61 \pm 0.02$ & $3.40 \pm 0.01$ & 0 & $40.69 \pm 0.02$ & 0.8 \\
\hline
\end{tabular}

*Calculated by difference: $\% \mathrm{O}=100-[(\mathrm{C}+\mathrm{H}+\mathrm{N}+\mathrm{S}) \%]$

radicals. ${ }^{23}$ Table 2 lists the values obtained for the number of spins $g^{-1}$ HA of free radicals, the values of $g$, and the spectral linewidth. The $g$ factor provides information about the chemical nature of the species that contains the unpaired electron, in the case of free radicals. Note the sloping baseline in the spectrum of the soil HA sample, which is due to overlapping of the signal (broadening) of $\mathrm{Fe}^{3+}$ at $g=2$, as indicated in Figure 4 .

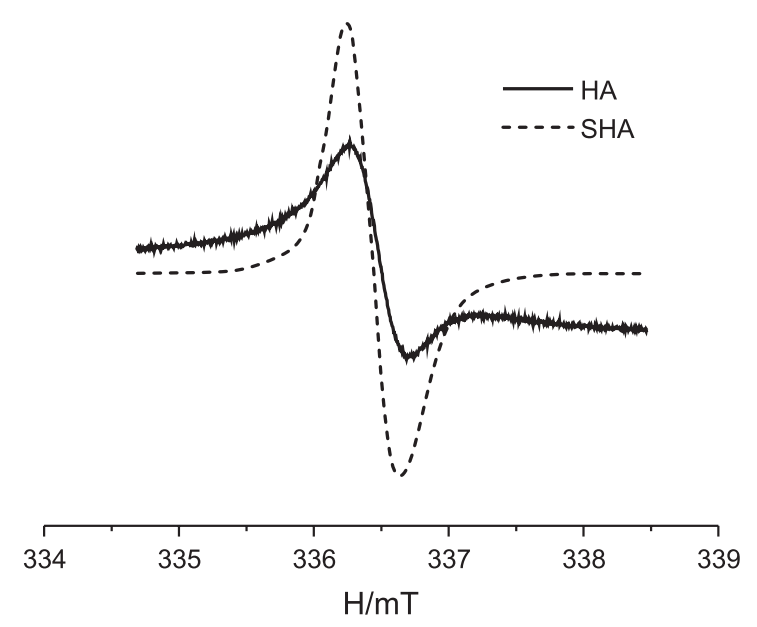

Figure 2. EPR spectrum of the humic acid (HA) sample extracted from soil, and of the sample synthesized from para-benzoquinone (SHA without metals), showing the free radical signal.

Table 2 indicates that the linewidth ranged from 0.395 to $0.418 \mathrm{mT}$ and the calculated $g$ factor was $c a .2 .003$, thus demonstrating that the paramagnetic resonance of the species, both in the humic acid (HA) sample extracted from soil and in the synthetic humic acid sample, has the same origin, i.e., it is the semiquinone free radical..$^{24} \mathrm{~A}$ comparison of the spectra in Figure 2 indicates a similarity between the HA spectrum and that of the SHA. Thus, the present data clearly shows that SHA can serve as a good model of the radical of the HA. There was a higher concentration of spins in SHA than in HA, but this apparently lower degree of humification of the sample of natural humic acid may be due to suppression of the EPR signal by paramagnetic ions. ${ }^{25}$ Natural humic acid and SHA probably contain more aromatic and carboxylic groups. According to the literature, the content of carboxylic and aromatic groups increases as the humification process advances, ${ }^{26,27}$ because these groups
Table 2. Organic free radical content, linewidth, and $g$ factor for humic acid (HA) from soil and synthetic humic acid (SHA)

\begin{tabular}{lccc}
\hline Sample & $\begin{array}{c}\text { No. of spins } g^{-1} \\
\text { HA, SHA }\end{array}$ & $\begin{array}{c}\text { Linewidth (mT) } \\
\text { (HA, SHA) }\end{array}$ & $g$ \\
\hline HA & $2.39 \times 10^{17}$ & 0.418 & 2.0032 \\
SHA & $8.72 \times 10^{18}$ & 0.395 & 2.0035 \\
\hline
\end{tabular}

are constituents of lignin, whose content diminishes with the transformations of organic matter in soil. ${ }^{27}$

\section{Study of synthetic humic acid with complexed metals}

The complexation of copper ions with SHA is favored because the structure obtained for the synthetic humic acid prepared from the $p$-benzoquinone precursor has a predominance of oxygenated groups. In the spectrum measured for SHA complexed with copper, we found that these can be formated of copper-oxygen complex. The value of $g_{/ /}$decreases as the number of $\mathrm{N}$ atoms increases, instead of oxygen, coordinated in the equatorial position, and the value of $\mathrm{A}_{/ /}$increases. ${ }^{925}$ Martin-Neto et al. ${ }^{28}$ found $\mathrm{a} \mathrm{Cu}^{2+}$ complex with an axial symmetry, with $g=2.28$ and $\mathrm{A}=17 \mathrm{mT}$, in which the copper was coordinated with nitrogen atoms. Figure 3 shows the spectrum of the SHA samples complexed with $\mathrm{Cu}^{2+}$, showing a value of $g_{\|}=2.32$ and $\mathrm{A}_{/ /}=14.3 \mathrm{mT}$, which are similar parameters as those

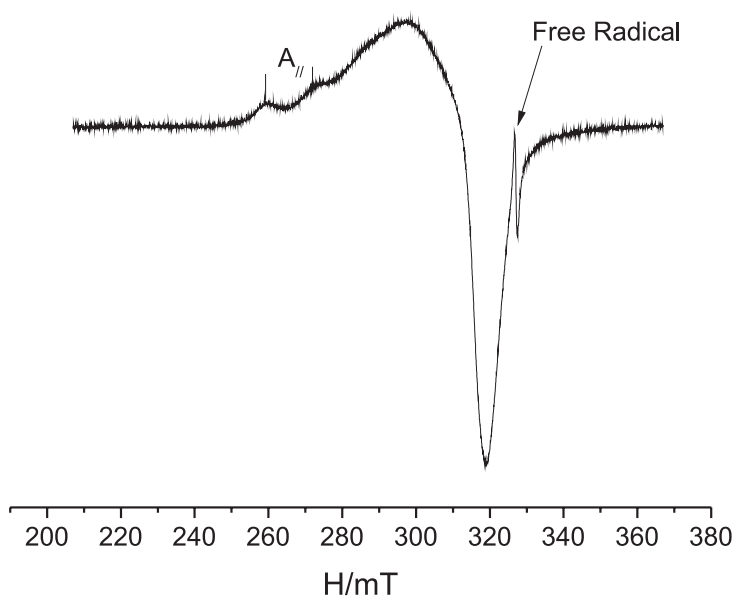

Figure 3. EPR spectrum of the SHA sample complexed with copper: $\mathrm{T}=90 \mathrm{~K}$ and $\mathrm{A}_{/ /}$is hyperfine coupling. 
found by Boyd et al. ${ }^{29}$ Senesi et al. ${ }^{30}$ and Senesi et al. ${ }^{9}$ for complexes of humic substances with $\mathrm{Cu}^{2+}$ coordinated with oxygen.

Figure 4 shows the spectrum of HA from soil (4a) and SHA complexed with $\mathrm{Fe}^{3+}(4 \mathrm{~b})$ in the region of the $\mathrm{Fe}^{3+}$ signals, indicating the values of $g=4.3$ and $g=2$. The $g=4.3$ is due to $\mathrm{Fe}^{3+}$ with a rhombic symmetry, while $g=2$ is probably due to the $\mathrm{Fe}^{3+}$ ion in the form of oxide. ${ }^{31}$ Note that the HA from soil and the synthetic HA with $\mathrm{Fe}^{3+}$ ions show similar signals, indicating that in the soil HAs can be happening the same types of retention of iron ions and native HAs.

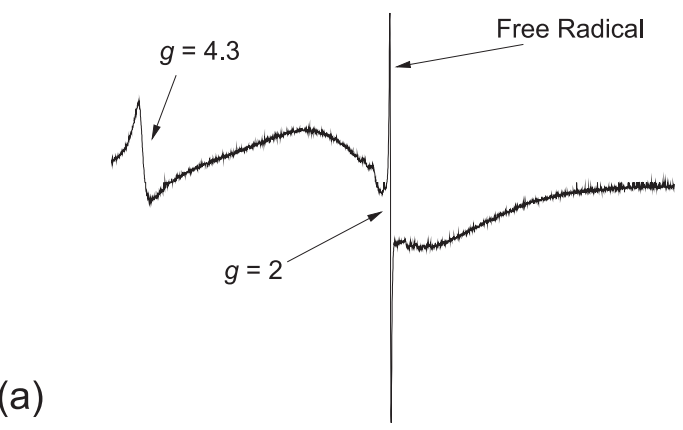

\begin{tabular}{rrrr}
\hline 100 & 300 & 400 & 500 \\
& & 1 \\
& &
\end{tabular}

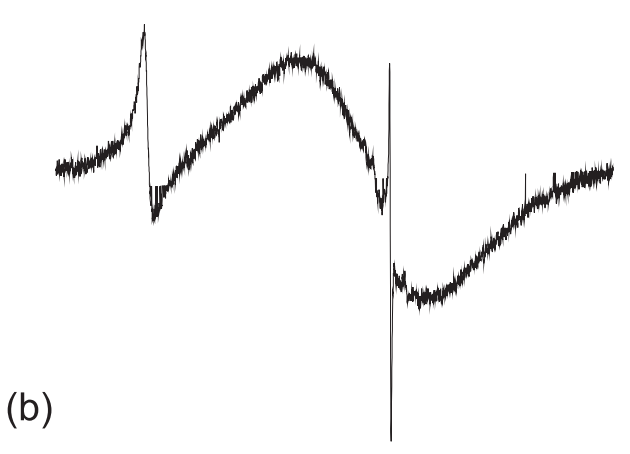

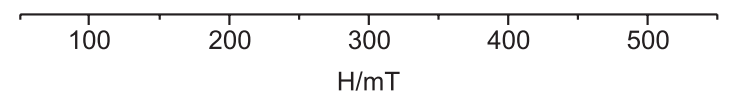

Figure 4. EPR spectrum of (a) the HA sample extracted from soil, and (b) SHA with iron.

Figure 5 depicts the EPR signal of the $\mathrm{Mn}^{2+}$ ion complexed in the SHA with hyperfine A $=8.7 \mathrm{mT}$. The EPR spectrum of $\mathrm{Mn}^{2+}$ is readily recognized in humic acids by its six hyperfine lines centered around $g=2 . \mathrm{Mn}^{2+}$ signals are not usually found in purified HA from soil. ${ }^{32}$ Values of A between 8.4 and $8.8 \mathrm{mT}$ to HA indicate complex in inner sphere and the functional groups possibly involved they would be carboxylic, hydroxyls phenolic and carbonyl. ${ }^{22}$

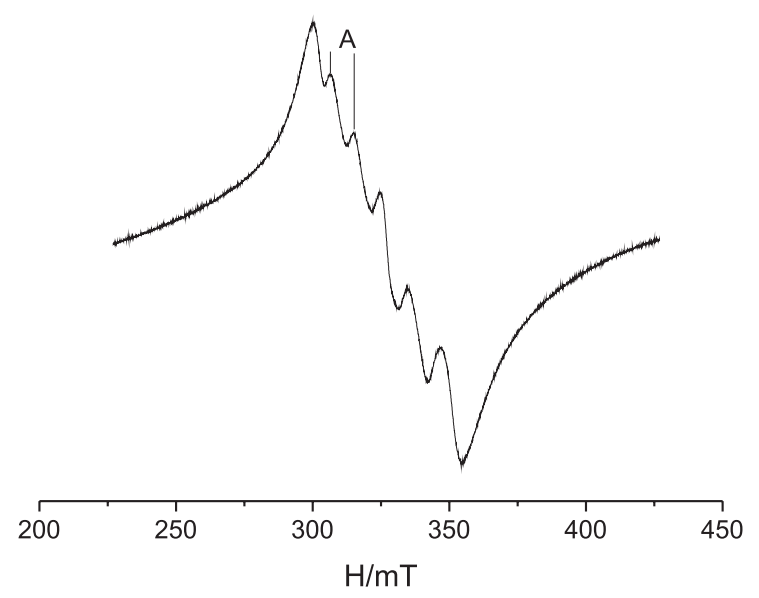

Figure 5. EPR spectrum of the SHA sample with manganese.

\section{Conclusions}

In this work, using the technique of EPR, the humic acid produced at laboratory with polymeric of parabenzoquinone, structural likeness was shown with humic acid from soil. The sign of the free radical was identified in SHA and with parameters similar to the found in the sign of soil HA. When complexed SHA with metals $\mathrm{Fe}^{3+}$, $\mathrm{Cu}^{2+}$ and $\mathrm{Mn}^{2+}$ identified characteristic signs of these metals when accomplished measures with soil HA.

\section{Acknowledgments}

The authors are indebted to Otaciro Rangel Nascimento for making the EPR facilities available. We gratefully acknowledge CAPES-PRODOC (Coordenação de Aperfeiçoamento de Pessoal de Nível Superior) and CNPq (Conselho Nacional de Desenvolvimento Científico e Tecnológico) for their financial support, and Embrapa (Empresa Brasileira de Pesquisa Agropecuária) for its structural support.

\section{References}

1. Stevenson, F. J.; Humus Chemistry. Genesis, Composition, Reactions, John Wiley: New York, 1994.

2. Cosovic, B.; Vojvodic, V.; Boskovic, N.; Plavsic, M.; Lee, C.; Org. Geochem. 2010, 41, 2000.

3. Giannakopoulos, E.; Drosos, M.; Deligiannakis, Y.; J. Colloid Interface Sci. 2009, 336, 59.

4. Wang, M. C.; Huang, P. M.; Geoderma 2003, 112, 31.

5. Wunderwald, U.; Kreisel, G.; Braun, M.; Schulz, M.; Appl. Microbiol. Biotechnol. 2000, 53, 441.

6. Hanninen, K. I.; Klöcking, R.; Helbig, B.; Sci. Total Environ. 1987, 62, 201. 
7. Zunino, H.; Aguilera, M.; Caiozzi, M.; Peirano, P.; Borie, F.; Martin, J. P.; Soil Sci. 1979, 128, 257.

8. Rosa, A. H.; Simões, M. L.; de Oliveira, L. C.; Rocha, J. C.; Martin-Neto, L.; Milori, D. M. B. P.; Geoderma 2005, 127, 1.

9. Senesi, N.; Adv. Soil Sci. 1990, 14, 77.

10. Czechowiski, F.; Iwona, G.; Jezierski, A.; Spectrochim. Acta, Part A 2004, 60, 1387.

11. Martin-Neto, L.; Vaz, C. M. P.; Crestana, S.; Instrumentação Avançada em Ciência do Solo, Embrapa Instrumentação Agropecuária: São Carlos, 2007.

12. MacCarthy, P. In Soil Sampling and Methods of Analisys; Carter, M. R.; Gregorich, E. G., eds.; Canadian Society of Soil Science, CRC Press: USA, 2008.

13. Anderson, D. W.; Schoenau, J. J. In Soil Sampling and Methods of Analisys; Carter, M. R.; Gregorich, E. G., eds.; Canadian Society of Soil Science, CRC Press: USA, 2008.

14. Stevenson, F. J.; Humus Chemistry: Genesis, Composition, Reactions, Wiley: New York, 1982.

15. Venancio, E. C.; Consolin Filho, N.; Constantino, C. J. L.; Martin-Neto, L.; Mattoso, L. H. C.; J. Braz. Chem. Soc. 2005, 16, 24.

16. Antilén, M.; Armijo, F.; J. Appl. Polym. Sci. 2009, 113, 3619.

17. MacCarthy, P.; Rice, J. A. In Humic Substances in the Global Environment and Implications on Human Health; Senesi, N., Eds.; Elsevier: Amsterdam, 1994.

18. http://ihss.gatech.edu/ihss2/soilhafa.html, accessed in March 2010.
19. Singer, L.S; J. Appl. Phys. 1959, 30, 1463.

20. Martin-Neto, L.; Rosell, R.; Sposito, G.; Geoderma 1998, 81, 305.

21. Cataldo, F.; Polym. Int. 1998, 46, 263.

22. Schnitzer, M.; Kahn, S. U.; Soil Organic Matter, Elsevier Scientific: Amsterdam, 1978.

23. Saab, S. C.; Martin-Neto, L.; Quim. Nova 2003, 26, 497.

24. Saab, S. C.; Martin-Neto, L.; J. Braz. Chem. Soc. 2004, 15, 34.

25. Novotny, E. H.; Martin-Neto, L.; Geoderma 2002, 106, 305.

26. Catroux, G.; Schnitzer, M.; Soil Sci. Soc. Am. J. 1987, 51, 1200.

27. Zech, W.; Senesi, N.; Guggenberger, K. K.; Lehmann, J.; Miano, T. M.; Miltner, A.; Schroth, G.; Geoderma 1997, 79, 117.

28. Martin-Neto, L.; Nascimento, O. R; Talamoni, J.; Poppi, N. R.; Soil Sci. 1991, 151, 369.

29. Boyd, S. A.; Sommers, L. E.; Nelson, D. W.; West, D. X.; Soil Sci. Soc. Am. J. 1983, 47, 43.

30. Senesi, N.; Sposito, G.; Martin, J. P.; Sci. Total Environ. 1986, 55,351 .

31. Saab, S. C.; Martin-Neto, L.; J. Braz. Chem. Soc. 2008, 19, 413.

32. Moreira, S. G.; Prochnow, L. I.; Kiehl, J. C.; Martin-Neto, L.; Pauletti, V.; R. Bras. Ciênc. Solo 2006, 30, 121.

Submitted: April 22, 2010

Published online: September 14, 2010

FAPESP has sponsored the publication of this article. 